Supplemental Table S1. Sources and unit costs of health care resources

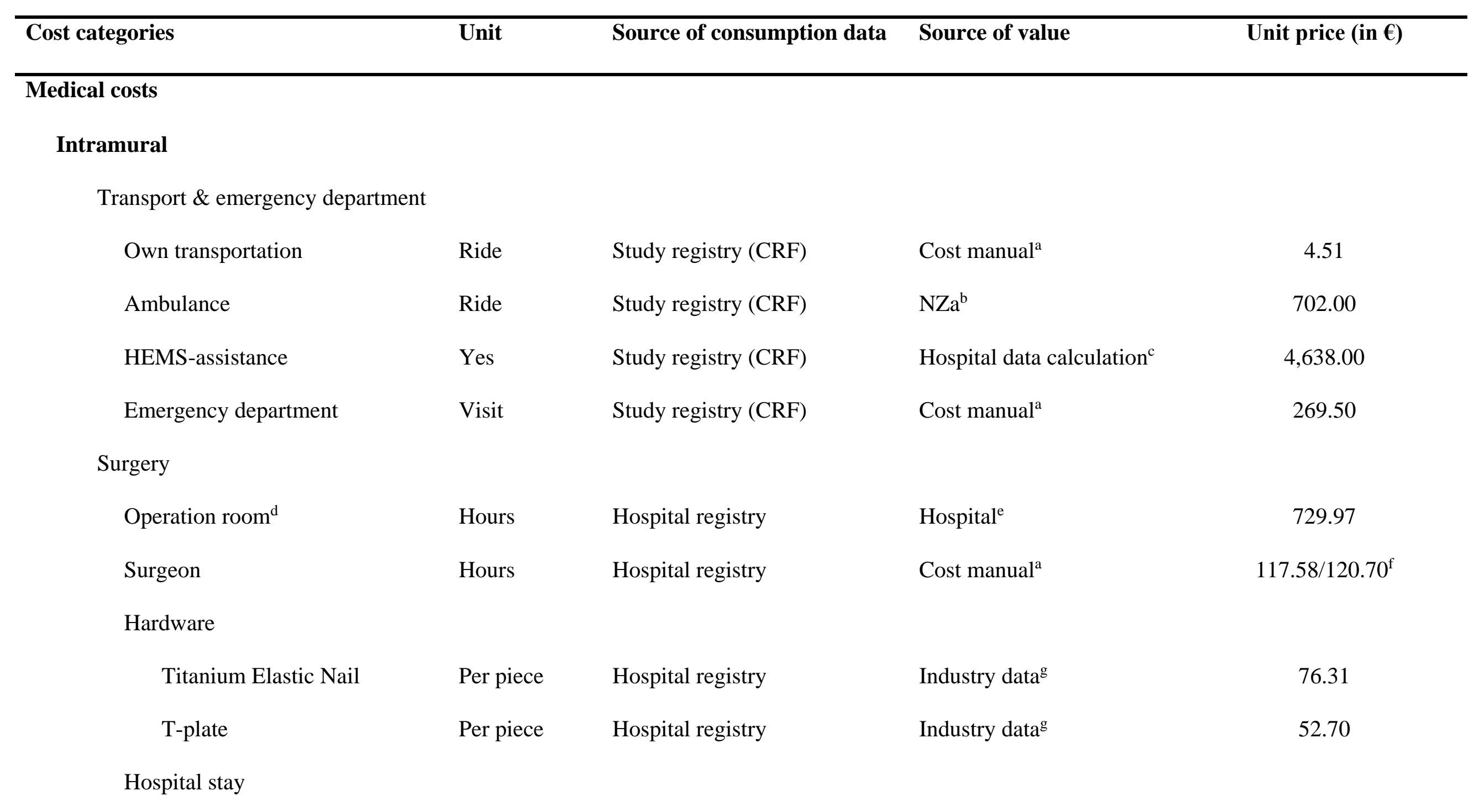




\begin{tabular}{|c|c|c|c|c|}
\hline General hospital & Days & Hospital registry & Cost manual $^{\mathrm{a}}$ & 460.96 \\
\hline Academic hospital & Days & Hospital registry & Cost manual ${ }^{\mathrm{a}}$ & 668.03 \\
\hline Burn center & Days & Hospital registry & Hop et al. 2016 [1] & $1,021.20$ \\
\hline Eye hospital & Days & Hospital registry & Hospital data ${ }^{\mathrm{h}}$ & $18,97.00 / 3,313.00 / 8,805.00^{\mathrm{i}}$ \\
\hline Intensive Care Unit & Days & Hospital registry & Hospital data ${ }^{j}$ & $3,195.02^{\mathrm{k}}$ \\
\hline \multicolumn{5}{|l|}{ utpatient clinic visits } \\
\hline General hospital & Visits & Hospital registry & Cost manual $^{\mathrm{a}}$ & 83.24 \\
\hline Academic hospital & Visits & Hospital registry & Cost manual ${ }^{\mathrm{a}}$ & 169.61 \\
\hline Burn center & Visits & Hospital registry & Hospital data $^{j}$ & 147.09 \\
\hline Eye hospital & Visits & Hospital registry & Hospital data ${ }^{\mathrm{h}}$ & 88.00 \\
\hline Hand therapist & Visits & Hospital registry & Hospital data $^{\mathrm{j}}$ & 40.31 \\
\hline Edema therapist & Visits & Hospital registry & Hospital data $^{\mathrm{j}}$ & 40.31 \\
\hline \multicolumn{5}{|l|}{ amural } \\
\hline Seneral practitioner & Visits & Patient questionnaire ${ }^{1}$ & Cost manual $^{\mathrm{a}}$ & 34.34 \\
\hline hysical therapist & Visits & Patient questionnaire ${ }^{1}$ & Cost manual $^{\mathrm{a}}$ & 34.34 \\
\hline ccupational therapist & Visits & Patient questionnaire ${ }^{1}$ & Cost manual $^{\mathrm{a}}$ & 34.34 \\
\hline
\end{tabular}




\begin{tabular}{|c|c|c|c|c|}
\hline Hand therapist & Visits & Patient questionnaire ${ }^{1}$ & Cost manual $^{\mathrm{a}}$ & 34.34 \\
\hline Psychologist & Visits & Patient questionnaire $^{1}$ & Cost manual $^{\mathrm{a}}$ & 34.34 \\
\hline Visio eye rehabilitation & Visits & Patient questionnaire ${ }^{1}$ & Cost manual ${ }^{\mathrm{a}}$ & 66.59 \\
\hline Social worker & Visits & Patient questionnaire ${ }^{1}$ & Cost manual $^{\mathrm{a}}$ & 67.63 \\
\hline Company doctor & Visits & Patient questionnaire ${ }^{1}$ & Cost manual ${ }^{\mathrm{a}}$ & 54.11 \\
\hline Medication & Dose per day & Hospital registry/ & $\mathrm{ZiN}^{\mathrm{m}}$ & Variable \\
\hline
\end{tabular}

\title{
Work absence
}
Wage
Hour
N.A.
Cost manual ${ }^{\mathrm{a}}$
$39.44 / 32.99^{\mathrm{n}}$

\begin{abstract}
Reference unit prices are adjusted to 2018 by using the national consumer price index.
CRF, Case Report Form.

N.A., Not applicable.

${ }^{\text {a }}$ Costing manual: Methodology of costing research and reference prices for economic evaluations in healthcare, version 2016 [2].

${ }^{\mathrm{b}}$ NZa, Nederlandse Zorgautoriteit [in English: Dutch Healthcare Authority): Standard costs prices, online available on:

https://puc.overheid.nl/nza/doc/PUC_6237_22/.
\end{abstract}

${ }^{c}$ HEMS, Helicopter Emergency Medical Service: based on costs hospital 2003-2006 
${ }^{\mathrm{d}}$ Including operating room personnel and overhead costs.

${ }^{\mathrm{e}}$ The Eye hospital provided a complete calculation of the surgery costs. These costs were used. For all other hospitals the surgery costs were calculated by multiplying the sum of the overhead costs and the hourly wage of the surgeon with the gross operation time.

${ }^{\mathrm{f}}$ Hourly wage for respectively an academic and non-academic surgeon.

${ }^{\mathrm{g}}$ Hardware costs were provided by the applicable firm.

${ }^{\mathrm{h}}$ The Eye Hospital Rotterdam: Passanten prijslijst 2018, online available on:

https://www.oogziekenhuis.nl/system/files/inline/Passanten\%202018\%20website\%20v1.4.pdf.

${ }^{\mathrm{i}}$ Admission for respectively 1-2 days, 3-5 days, or $>5$ days.

${ }^{\mathrm{j}}$ Maasstad Hospital: Passanten prijslijst 2018, online available on: https://www.maasstadziekenhuis.nl/media/5958/passanten-01-01-2018-31-122018_v2.pdf.

${ }^{\mathrm{k}}$ ICU admission for Burn Center Maasstad Hospital only.

${ }^{1}$ A customized version of the iMTA Questionnaires for the measurement of costs in economic evaluations (based on the Medical Consumption Questionnaire and Productivity Cost Questionnaire) [3, 4].

${ }^{\mathrm{m}} \mathrm{ZiN}=$ Zorginstituut Nederland [in English: National Healthcare Institute] - Standard prices were used, online available on: www.medicijnkosten.nl.

${ }^{\mathrm{n}}$ National average hourly wage for respectively males and females. 


\section{References}

1. Hop MJ, Wijnen BF, Nieuwenhuis MK, Dokter J, Middelkoop E, Polinder S, et al. Economic burden of burn injuries in the Netherlands: A 3 months follow-up study. Injury. 2016;47(1):203-10.

2. Hakkaart-van Roijen L, Van der Linden N, Bouwmans C, Kanters T, Tan SS. Costing manual: Methodology of costing research and reference prices for economic evaluations in healthcare [in Dutch: Kostenhandleiding: Methodologie van kostenonderzoek en referentieprijzen voor economische evaluaties in de gezondheidszorg]. 2016.

3. Questionnaires for the measurement of costs in economic evaluations: institute for Medical Technology Assessment; [Available from: https://www.imta.nl/questionnaires.

4. Bouwmans C, Krol M, Brouwer W, Severens JL, Koopmanschap MA, Hakkaart L. IMTA Productivity Cost Questionnaire (IPCQ). Value Health. 2014;17(7):A550. 